pressure difference would be comparable with the atmospheric pressure is of molecular order of size or smaller.

Institute of Physics,

I. KUگ̌̌̌R

University of Ljubljana, Yugoslavia.

1 Schmidt, W., Nature, 137, 777 (1936).

${ }^{2}$ Compare with Lamb-Oseen's solution for the cylinder. See, for example, Míller W. " "Einführung in die Theoric der zähen Flüssigample, ,MüLer, W., "Einführing

"See, for example, Adam, N. K., "The Physics and Chemistry of Surfaces", 212 (London, 1944).

\section{Mechanical Degradation of Large Molecules}

Frov the thermo-chemical data for the strength of the carbon-carbon single bond (about $5 \times 10^{-3}$ dynes), the rate of shear was estimated for rupturing the centre bond of large hydrocarbon molecules in solution under laminar flow conditions owing to the component of the viscous drag in the direction of the long axis of the molecule. Experiments confirmed the calculated order of magnitude of the critical value of the rate of shear as a function of the chainlength of the molecule.

Tabie 1. Perchntage permanent viscostty-loss at $20^{\circ} \mathrm{C}$. With THE NUMBER OF PASSAGES OF THE LIQUID THROUGH THE JET FOR A 5 PER CENT SOLUTION OF A POLYMER HAVING AN AVERAGE MOLECULAR WHIGHT ABOVE 100,000 WITH AN INITIAL MEAN RATE OF SHEAR OF $1.75 \times 10^{8}$ SEC. $^{-1}$

\begin{tabular}{|c|c|c|c|}
\hline $\begin{array}{c}\text { Apparent per- } \\
\text { centage perman- } \\
\text { ent viscosity loss } \\
\text { from (pt)-values* }\end{array}$ & $\begin{array}{c}\text { Number of } \\
\text { cycles through } \\
\text { jet }\end{array}$ & $\begin{array}{c}\text { Percentage per- } \\
\text { manent viscosity } \\
\text { loss at low rates } \\
\text { of shear }\end{array}$ & $\begin{array}{c}\text { Viscosity- } \\
\text { temperature } \\
\text { coefficient }\end{array}$ \\
\hline 0 & 0 & 0 & $-1 \cdot 770$ \\
$4 \cdot 8$ & 6 & & \\
$6 \cdot .3$ & 7 & & \\
6.3 & 8 & & \\
7.8 & 9 & & \\
7.8 & 11 & & \\
7.9 & 12 & & \\
8.2 & 13 & & \\
10.0 & 18 & & \\
10.6 & 25 & & \\
11.1 & 28 & & \\
11.1 & 30 & & \\
11.3 & 56 & & \\
13.7 & 70 & & \\
13.8 & 71 & & \\
15.0 & 72 & & \\
13.9 & 102 & & \\
15.2 & 103 & & \\
15.8 & 10.8 & \\
\hline
\end{tabular}

* $p=$ pressure difference across jet in $\mathrm{cm}$. mercury, $t=$ time of flow in seconds. The permanent decrease of the $(p t)$-values of very long molecules (length of the order of 1 per cent of the diameter of the jet) is always larger than the permanent viscosity-loss measured at low rates of shear because turbulence arises with these long molecules even at very low Reynolds' numbers. With the degradation of the molecules this tendency to turbulence becomes reduced.

With an apparatus ${ }^{1}$ giving mean rates of shear of the order of $10^{5} \mathrm{sec}^{-1}$ under laminar flow conditions, long-chain molecules of molecular weights above 100,000 were broken down (Table 1), yielding an exponential type of decay curve for the percentage permanent viscosity-loss plotted as a function of the number of eycles of forcing the solution in individual drops through a jet. The mechanical degradation was assessed by the permanent viscosityloss of the solutions at low rates of shear, by the accompanying increase of the viscosity-temperature coefficient of the solutions and by the displacement of the transition region from laminar to turbulent flow towards higher values of the rate of shear as the result of rupturing the largest molecules.

According to the simplifying assumptions made for the calculations, the stretching forces reached their largest value for the centre chemical bond and would increase with the square of the length of the molecule for a given value of the shearing stress. Thus, rates of shear of more than $1.6 \times 10^{6} \mathrm{sec}^{-1}$ would be required for the breakdown of molecules of molecular weights of 25,000 and less.

Table 2. Peroentagr permanent viscosity-Loss with the Number OF PASSAGES OF THE MIOUTD THROUGH THE JWT FOR A 5 PER CENT SOLUTION OF A POLYMER HAVING AN AVERAGE MOLECULAR WEIGHT LESS THAN 25,000

\begin{tabular}{|c|c|c|c|}
\hline $\begin{array}{c}\text { Mean rate of } \\
\text { shear in sec. }\end{array}$ & $\begin{array}{c}\text { Percentage perm- } \\
\text { anent viscosity } \\
\text { loss at low rate of } \\
\text { shear and at } \\
37.8^{\circ} \mathrm{C} .\end{array}$ & $\begin{array}{c}\text { Number of } \\
\text { cycles }\end{array}$ & $\begin{array}{c}\text { Viscosity- } \\
\text { temperature } \\
\text { coefficlent }\end{array}$ \\
\hline 0 & 0 & 0 & $-2 \cdot 813$ \\
$3.823 \times 10^{\circ}$ & 3.4 & 500 & $-2 \cdot 846$ \\
$3.823 \times 10^{8}$ & $7 \cdot 0$ & 2500 & $-2 \cdot 882$ \\
$3.823 \times 10^{6}$ & 9.2 & 5000 & $-2 \cdot 907$ \\
\hline $6.324 \times 10^{\circ}$ & $6 \cdot 0$ & 1000 & $-2 \cdot 885$ \\
$6.324 \times 10^{\circ}$ & $12 \cdot 3$ & 5000 & $-2 \cdot 954$ \\
\hline $1 \times 10^{7}$ & $8 \cdot 0$ & 2000 & $-2 \cdot 912$ \\
$1 \times 10^{7}$ & $13 \cdot 0$ & 5000 & $-2 \cdot 979$ \\
\hline
\end{tabular}

With a high-pressure jet (to be described elsewhere) calculated to give rates of shear of the order of $10^{7}$ sec. $^{-1}$ for Poiseuille flow, materials of molecular weights of 25,000 and less which remained unaffected in the previous apparatus ${ }^{1}$ for rates of shear of the order of $10^{5}$ sec. $^{-1}$ were broken down (Table 2).

WILLIAM JOHN MORRIS

Physies Department, ROBERT SCHNURMANN

Manchester Oil Refinery Ltd., Manchester. July 15.

${ }^{2}$ Morris, W. J., and Schnurmann, R., Rev. Sci. Instr., 17, 17 (1946),

\section{Christiansen Filters for the Ultra-Violet}

Gaydon and Minkoff ${ }^{1}$ have described a Christiansen filter designed to isolate the $2537 \mathrm{~A}$. resonance line of mercury. We have been working for some time upon the general problem of the design of Christiansen filters for the isolation of various spark and discharge tube lines to be used in ultra-violet microscopy. We have amplified the work of Kohn and von Fragstein ${ }^{2}$, and developed a series of filters employing benzenealcohol mixtures with fused quartz chips, which can span the region 3000-4000 A.

The absorption of benzene prevents the use of this combination below $3000 \mathrm{~A}$. Therefore, we have developed a set of filters employing mixtures of purified decahydronaphthalene and cyclohexane,

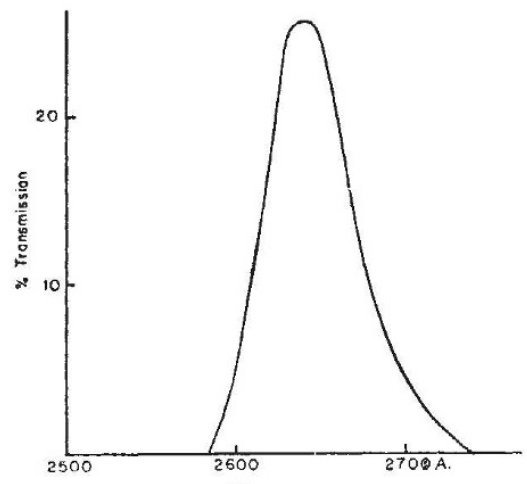

Fig. 1 